\title{
European Guest Lecture Subfoveal New Vessels in Age Related Macular Degeneration
}

\author{
G. COSCAS
}

Créteil

Age-related macular degeneration (AMD) is a major cause of blindness in the Western World. While only $10 \%$ of AMD patients have the exudative form of the disease, $88 \%$ of legal blindness, attributable to AMD, is due to this type. ${ }^{1}$ This exudative form is characterised by the presence of subretinal new vessels which leak serum, blood and lipids. Eventually, this exudative process leads to an organised scar tissue and the cicatricial disciform lesion results in significant and permanent loss of central vision.

Clinically, the wide spectrum of the exudative form comprises many different and varied patterns including choroidal neovascularisation, retinal pigment epithelium detachment and tears, fibrovascular disciform response and even vitreous haemorrhage.

The initial location of the subretinal new vessels (SNV) is probably the most important risk factor and will induce, more or less severe, clinical symptoms.

Previously published randomised controlled trials have brought evidence that for patients referred at an early stage there is a beneficial effect on visual outcome from focal laser treatment.

However, less than $20 \%$ of patients with new vessels, presenting in referral centres fulfill the criteria of these studies. ${ }^{2,3,4}$

Most of the patients $(58 \%)$ present with late stages of the disease process, involving not only the subfoveal area but the entire macular area.

Even newly symptomatic patients may have new vessels within the foveal avascular zone by the time they consult an ophthalmologist. The most important concern is about these subfoveal new vessels (Fig. 1).

They were, until recently, considered not to be amenable to laser treatment: complete obliteration was likely to result in an immediate and severe loss of vision. ${ }^{5}$

A precise diagnosis and classification system of subretinal neovascularisation in AMD is needed in order accurately to evaluate the natural history and to select appropriate management.

On fluorescein angiography, major types of new vessels are, at present, identifiable:

- visible or well defined SNV (that fill early with dye and leak profusely to the late phase). (Fig. 2a)

- occult or poorly defined SNV (that have less precise features on the early frames but give rise to late leakage). (Fig. 2b)

- visible SNV can be surrounded or can occur during the natural course, within an area of occult new vessels. (Fig. 2c)

- vascularised pigment pigment epithelial detachments can contain either visible or, more frequently, subretinal neovascular membranes (which may be partially obscured by turbid or haemorrhagic fluid). (Fig. 2d)

Fluorescein angiography is of major value for the detection and precise location of the neovascular frond in relation to the centre of the foveal avascular zone.

Visible or well-defined neovascularisation fills early with dye, often in a cartwheel pat-

Presented at the Oxford Ophthalmological Congress, July, 1990.

Correspondence to: Clinique Ophtalmologique Universitaire, Université Paris XII, 40, avenue de Verdun, 94010 CRETEIL France. 


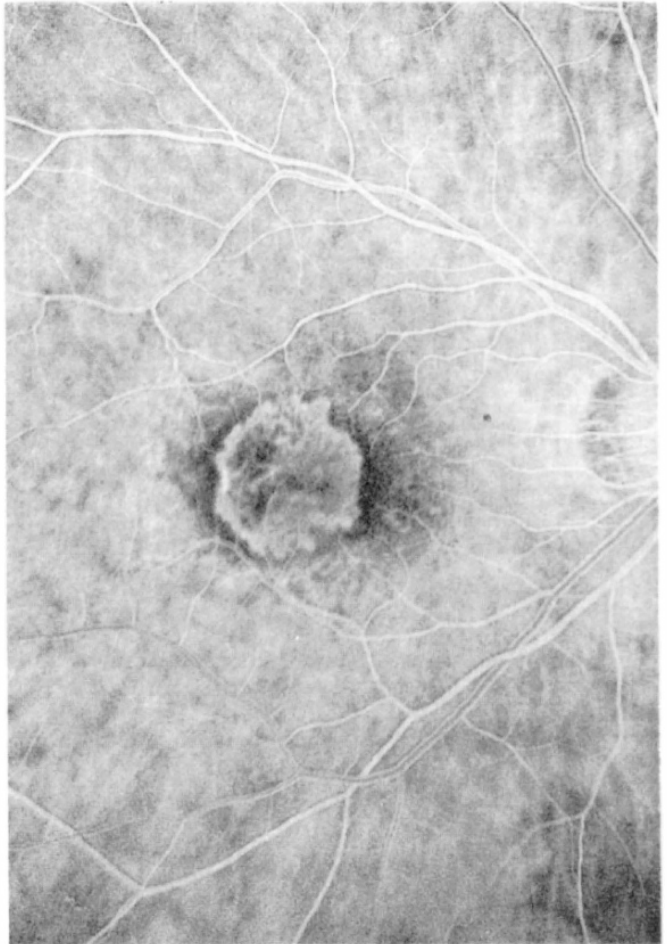

Fig Ia.

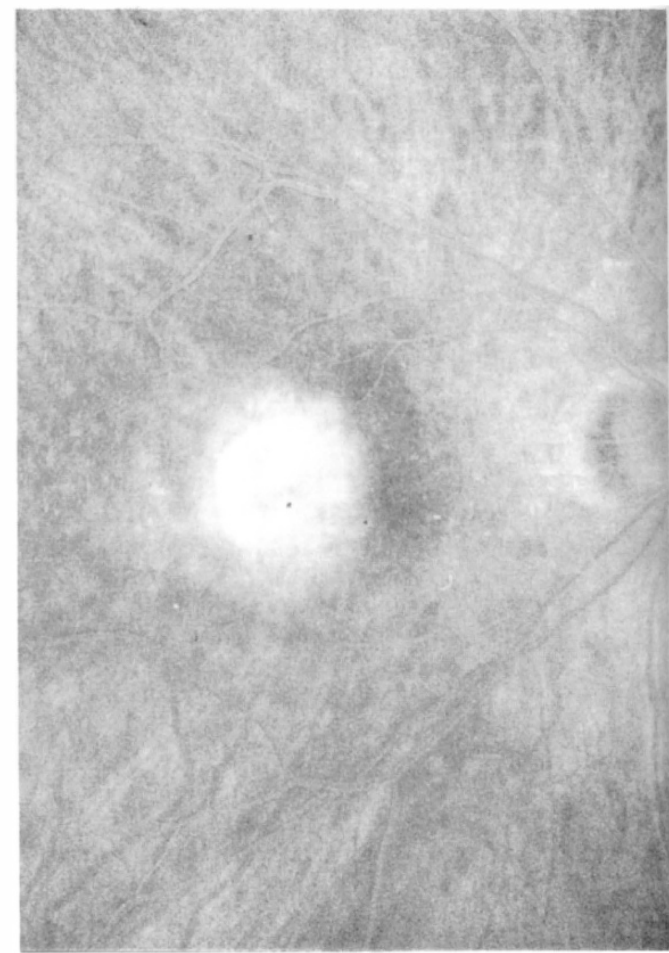

Fig $1 \mathrm{~b}$.

Fig. 1 (a,b). Subfoveal new vessels. Early and late angiogram.

tern and leaks profusely in the late phase of the angiogram. (Fig. 1)

Occult or ill-defined neovascularisation shows an irregular and uneven fluorescence in the early phase. Hyperfluorescent areas alternate with hypofluorescent areas. Leakage of dye, the hallmark of neovascularisation, is always present and frequently associated with very suggestive hyperfluorescent dots, but precise location is extremely difficult. (Fig. 3a,b)

The geographic borders of well-defined neovascular membranes can be evaluated during fluorescein angiography, particularly as they relate to the centre of the foveal avascular zone (the foveola), allowing one to determine and classify subretinal new vessels into four groups:

(1) extrafoveal at more than 400 microns from the foveola,

(2) juxta-foveal between 200 and 400 microns,
(3) juxta-foveolar between 5 and 200 microns and

(4) retrofoveolar, involving the centre.

- For extrafoveal subretinal new vessels located at more than 200 microns from the centre of the foveal avascular zone, Argon laser photocoagulation has proven its efficacy in reducing the risk of severe visual loss.

- The possible benefit of krypton laser photocoagulation is presently being evaluated for juxtafoveal subretinal new vessels, located at 1 to 200 microns from the centre of the FAZ.

- None of these studies have included eyes with subfoveal visible new vessels, directly under the anatomic centre of the fovea.

Subfoveal new vessels involve at least $50 \%$ of the FAZ and will extend to all the FAZ or beyond: new vessels are either emerging directly under the fovea or growing from an extrafoveal position toward the fovea.

It has been shown that $54 \%$ of visible new 


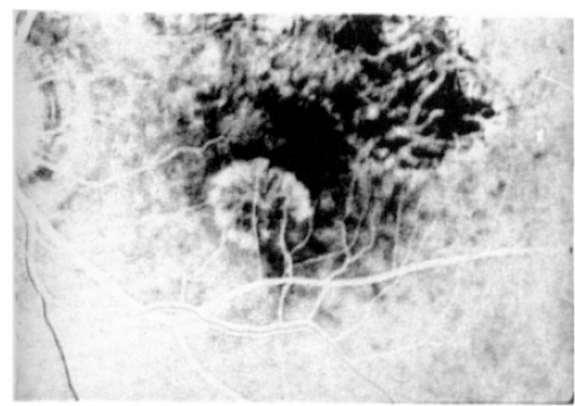

Fig. 2a.

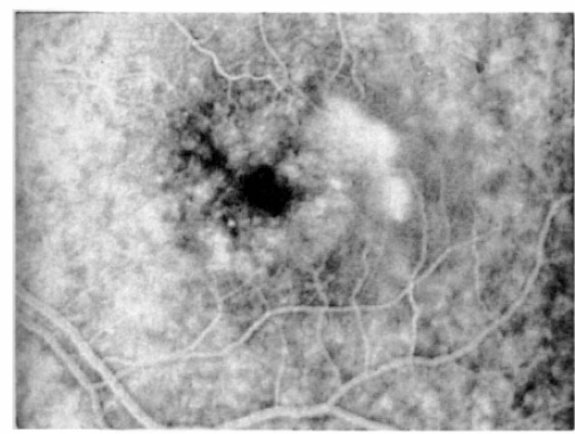

Fig 2c.

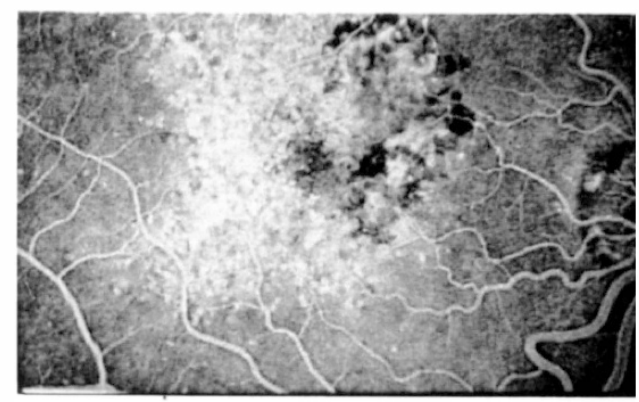

Fig. 2 h.

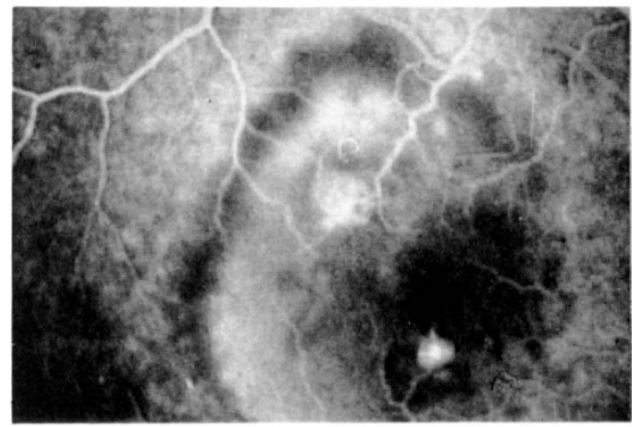

Fig 2d.

Fig. 2. Different types of macular subretinal new-vessels. (a) Visible or well-defined new-vessels. (b) Occult or poorly defined new-vessels. (c) Visible new-vessels occurring with an area of occult new vessels. (d) Vascularized pigment epithelial detachment.

vessels grow towards the fovea at a rate of 10 to 18 microns daily in a three-week period.

Furthermore, $73 \%$ of extrafoveal new vessels extend to a subfoveal location after one year.

Among membranes invading all the FAZ, three types can be considered:

- originating directly in the centre and limited to the FAZ;

- larger and involving all the macular area;

- or even more extensively to the entire posterior pole.

Natural history studies have demonstrated a poor visual prognosis for eyes with subfoveal membranes (Fig. 4a,b). Two retrospective studies ${ }^{6,7}$ have shown that most eyes became blind after a follow-up period of approximately two years:

$-54 \%$ of eyes with an initial acuity of 20 / 100 or better;

- All eyes (except one) with initial acuity worse than 20/100 remained blind;

- The number of eyes losing four to six lines acuity or more increased with the length of follow-up: this loss occurred in $77 \%$ of eyes re-examined 24 months following their initial presentation.

Furthermore, visual prognosis is closely related to the size of the membrane. If visual acuity, at presentation, was of $20 / 100$ or better:

$-38 \%$ of eyes with membrane of less than 1500 microns in size, retained the same visual acuity;

- Conversely, all the eyes with large membranes were legally blind after two years follow-up.

This is possibly due to the fact that large membranes have a higher growth rate than do smaller ones or that they were initially in an extra-foveal location.

In a group of 49 eyes, with subfoveal membranes less than 2,5 DD in size, that were the observed group of our clinical trial of perifoveal laser treatment, ${ }^{8}$ we noticed:

- deterioration of distance and reading 


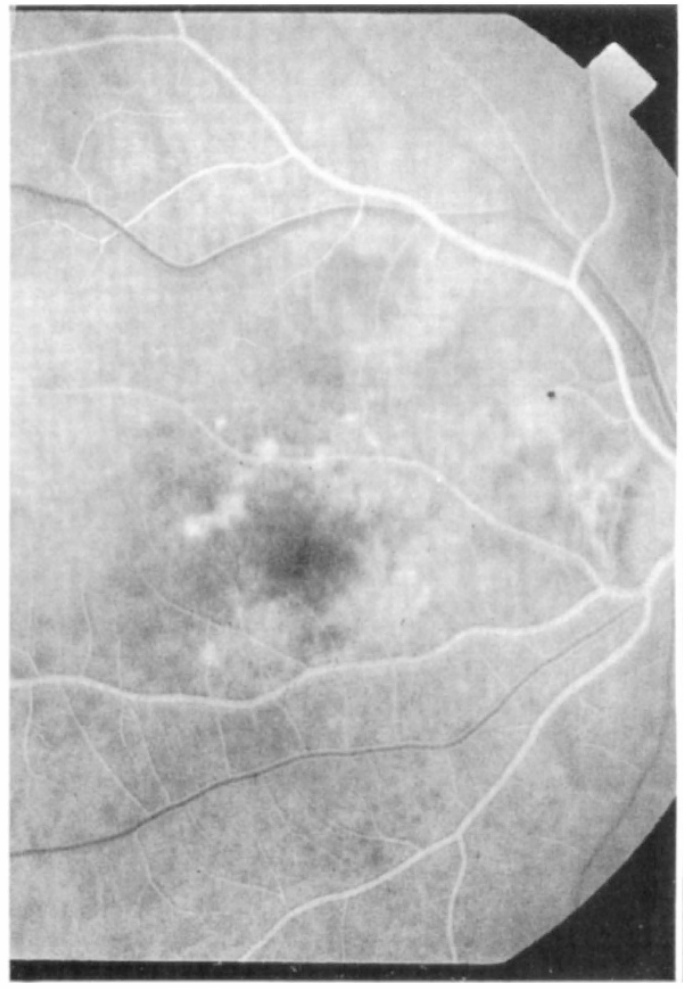

Fig 3a.

Fig. 3 (a,b). Occult subretinal macular new-vessels. Note the typical hyperfluorescent pin-points on late angiogram (b).

V.A. over a follow-up period of 12 to 25 months. Twenty nine out of 49 eyes $(59 \%)$ had a final visual acuity of less than $20 / 400$. Visual acuity was stable in only nine eyes and 23 eyes had lost six lines or more.

- On automatic static perimetry, all but four patients had an increase in size and/or depth of the scotoma with reduced sensitivity.

- Well defined new vessels grew and involved the macular area in 16 out of 25 eyes, associated with haemorrhages and fibrous tissue in half of the eyes.

- Ill-defined new vessels extended in 13 out of 24 eyes, involving the whole posterior pole in two eyes, and progressed to geographic atrophy in two other eyes.

In our long-term natural history study of subfoveal new vessels ( 2 to 10 years: mean 4 years) ${ }^{9}$

- visible new vessels progressed to a fibrovascular scar in 27 out of 33 eyes,

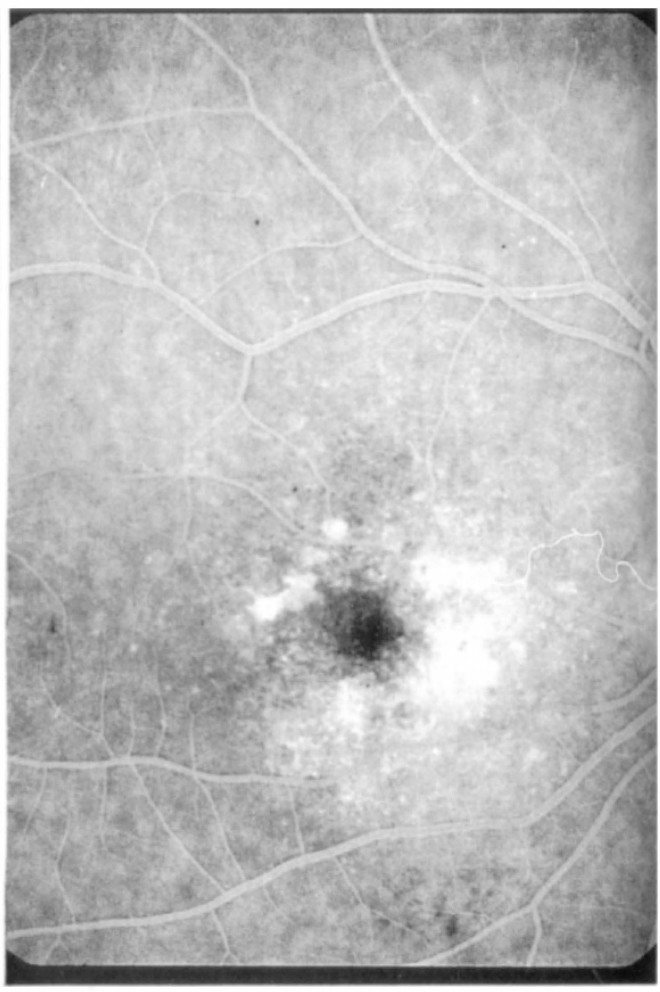

Fig 3b.

- a progressive growth of active new vessels was demonstrated on fluorescein angiography in $51 \%$, during the so-called cicatricial stage.

- significant enlargement of the disciform lesion was usual.

- Occult new vessels, in the same study, ${ }^{9}$ progressed equally to fibrovascular or to atrophic scars always with residual new vessels and with an enlargement of the macular involvement in most of the cases.

- Vascularised PED showed the worst natural course as most progressed to a large fibrovascular lesion almost always with residual new vessels.

Thus, the type of the scars was closely related to the initial type of new vessels and enlargement of the lesion. Only a few cases with a relatively slow and progressive course associated to ill-defined new vessels would result in an atrophic scar with residual vision. 


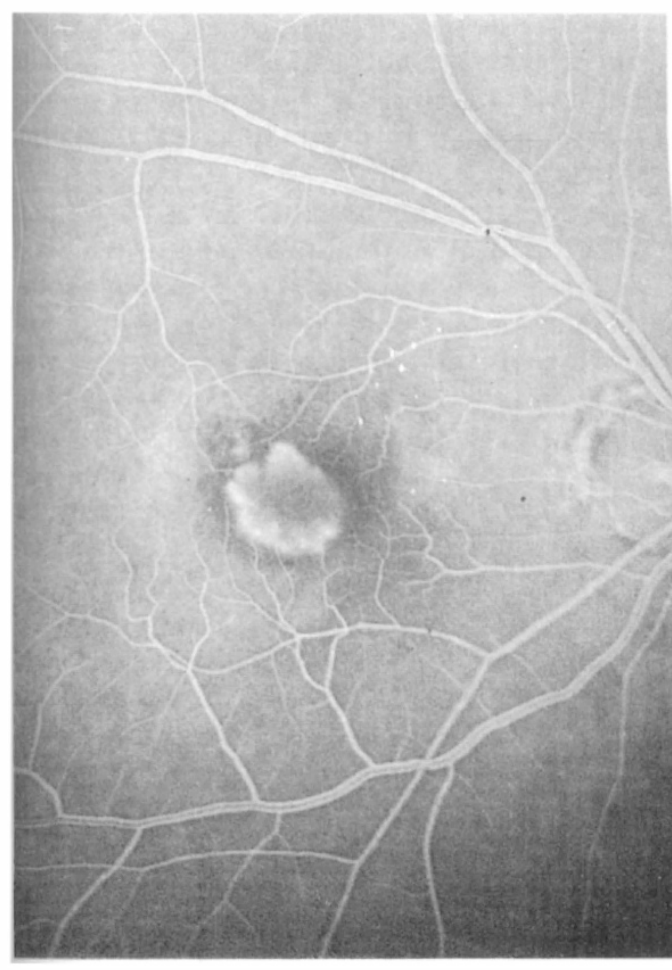

Fig tia.

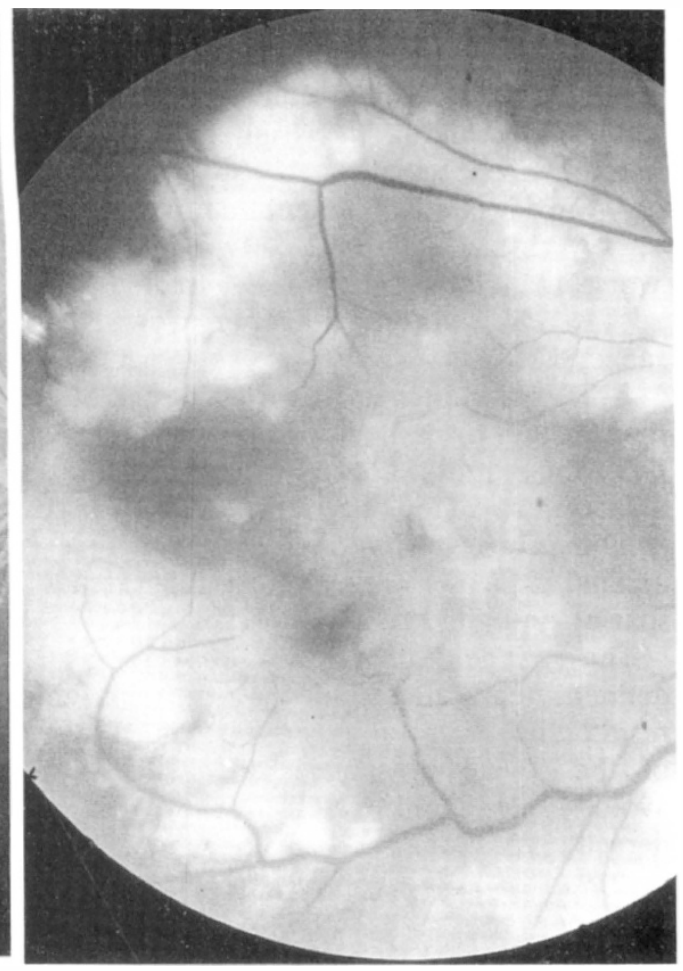

Fig th.

Fig. 4 (a,b). Severe natural history in eye with subfoveal membrane (a). Four years later, very large and extensive fibrovascular lesion (b).

The vast majority of eyes deteriorate very severely.

For eyes presenting with so-called cicatricial lesion, it is generally expected that the subfoveal neovascular complex involute and result into a reparative and cicatricial stage, with an elevated fibrovascular or a flat atrophic scar.

However, during our long-term follow-up study, we observed that, the fibrovascular scars remained active in most cases: new vessels were present and the disciform enlarged in half of the eyes.

Even the atrophic scars could enlarge in a comparable proportion. Moreover, geographic atrophy may give rise to new-vesselsgrowth, on its margins, as found in $20 \%$ of eyes, in our study.

Thus, the results of all the natural history studies clearly demonstrated a poor visual outcome with a progressive and long-term enlargement, haemorrhages and an increase of the central scotoma. ${ }^{9,10,11}$
Some eyes present with well defined tufts of new vessels within an area of occult new vessels. The natural history suggests that the visual prognosis depends on the well-defined component of the neovascular complex.

Therefore treatment was justified and partial or total destruction of the subfoveal new vessels resulted. ${ }^{12,13,14}$

Laser treatment approaches are still not clearly defined: partial photocoagulation of the visible new vessels alone does not seem satisfactory; and total laser treatment of both visible and occult new vessels results in extensive scarring.

The Foveal Photocoagulation Study (in USA) is currently investigating the value of complete laser treatment of these eyes. This treatment could result in a smaller final scotoma size and facilitate the use of low vision aids by preserving more parafoveal retina. Although this study was initiated in February 1986, there are still no data available.

Our treatment approach in Créteil was to 
occlude the large neovascular membranes with the perifoveal technique. ${ }^{15}$ Results of a randomised controlled clinical trial will be published soon. In this trial, eyes included had to present with:

- Subfoveal involvement due to AMD;

- A distance visual acuity equal to or worse than 20/100, but not less than 20/100;

- Reading vision had to be worse than Jaeger 6.

- The subretinal arcade extended at more than $200 \mu \mathrm{m}$ from the centre but less than 2.5 DD wide, without fibrous tissue. (Fig. 5a,b)

In order to stop the neovascular growth, confluent and overlapping laser burns were applied to the peripheral neovascular arcade, sparing only the FAZ.

The peripheral neovascular arcade of welldefined membranes could be destroyed and resulted in an atrophic scar. The central part of the foveal avascular zone which was avoided, could still exhibit a residual serous detachment, with little leakage. (Fig. 6a,b)

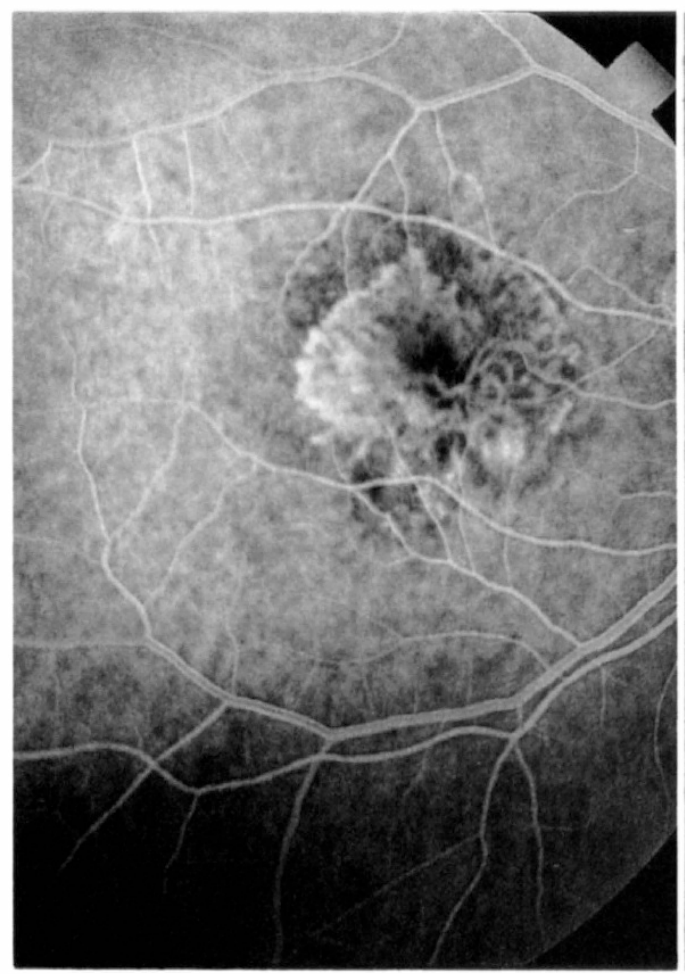

Fig 5a.
For ill-defined macular new vessels, laser burns were applied to their probable limits but always sparing the FAZ. Here also some central leakage of dye may have existed but which regressed progressively.

Automatic static perimetry was performed before and after treatment. (Fig. 7a,b) The scotoma increased immediately after photocoagulation and remained stable during follow-up. In 17 eyes, the scotoma was peri-centrally located with a relative central sparing and stable fixation.

The perifoveal treatment has proven beneficial in treated eyes in preserving distance and near vision (with low vision aids). Statistical significance was at a p level of 0.01 (distance) and 0.03 (near vision).

Complete obliteration of the new vessels and a flat atrophic scar was achieved in 49 out of the 56 treated eyes. Only two observed eyes (out of 49) progressed to an atrophic scar whereas 29 of these 49 eyes resulted in a macular disciform lesion.

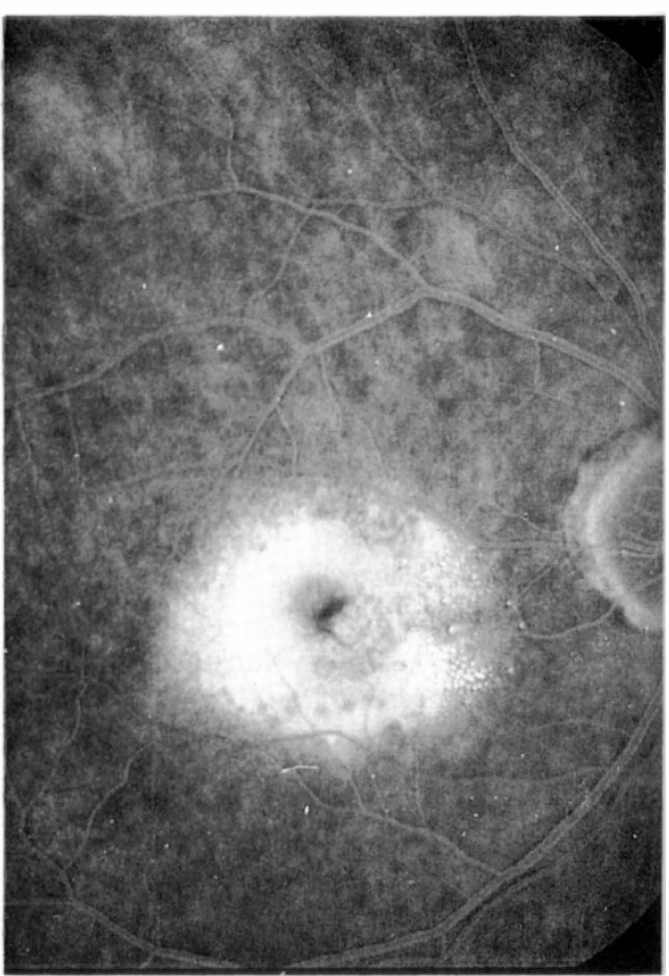

Fig 5h.

Fig. 5 (a,b). Subfoveal involvement with a 2 disc diameter neovascular membrane in age-related macular degeneration. (a) Early angiogram. (b) Late stage. 


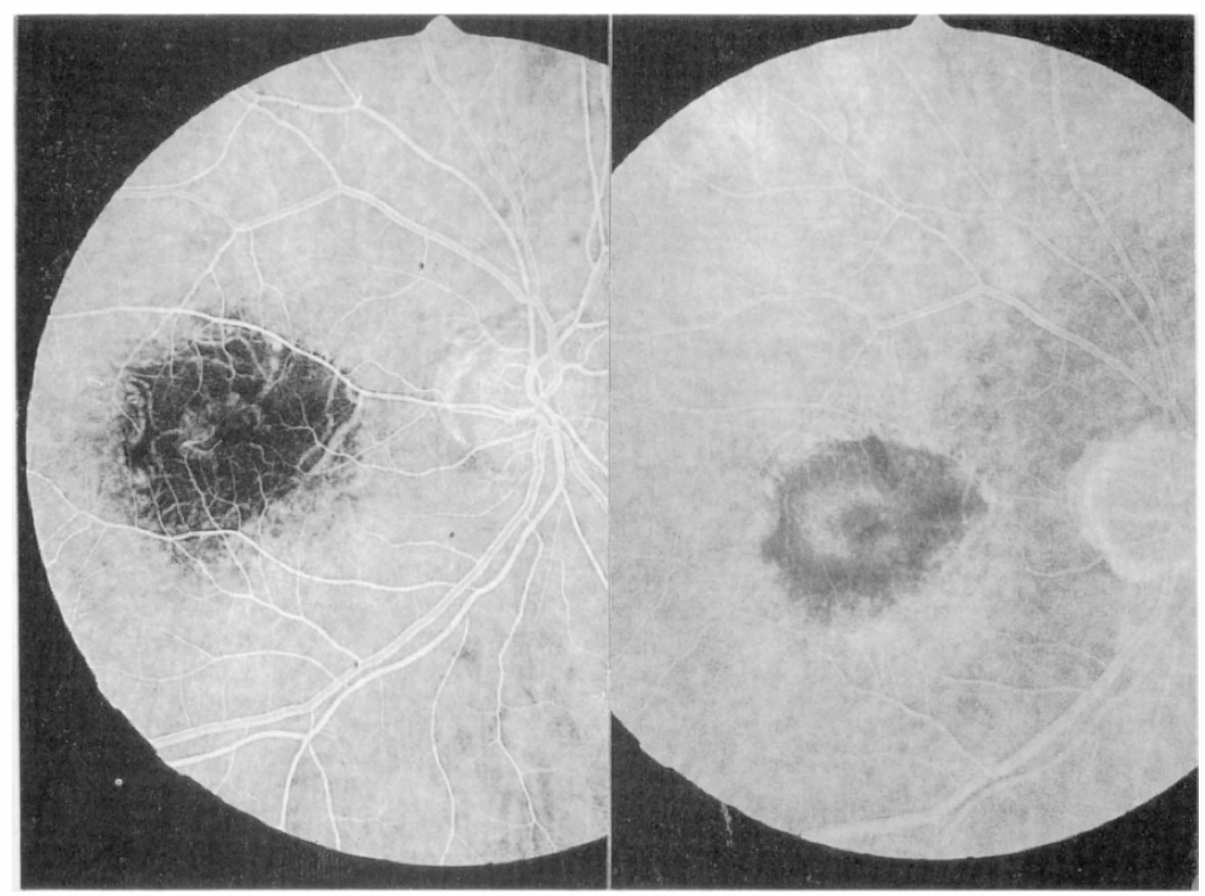

Fig 6a.

Fig 6b.

Fig. 6 (a,b). Same patient than Fig. 5, 15 days after perifoveal laser photocoagulation. Early (a) and late (b) angiogram.

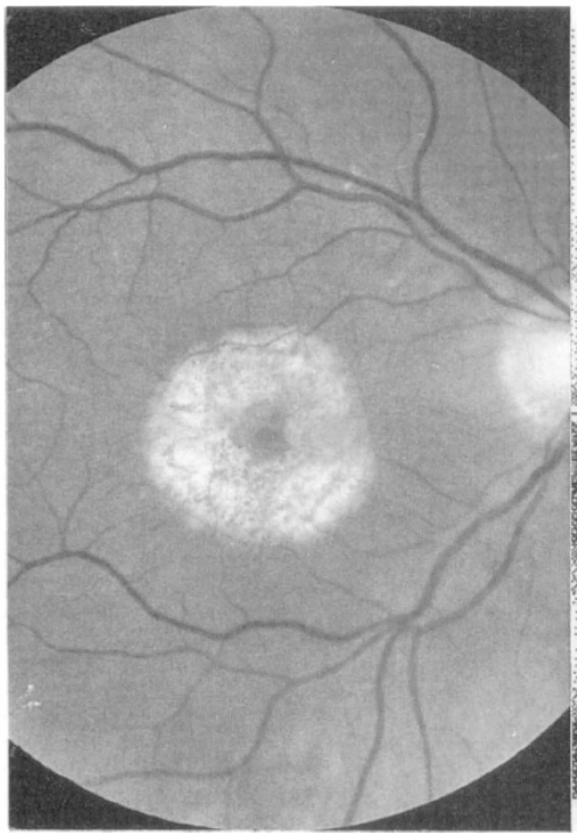

Fig 7a.

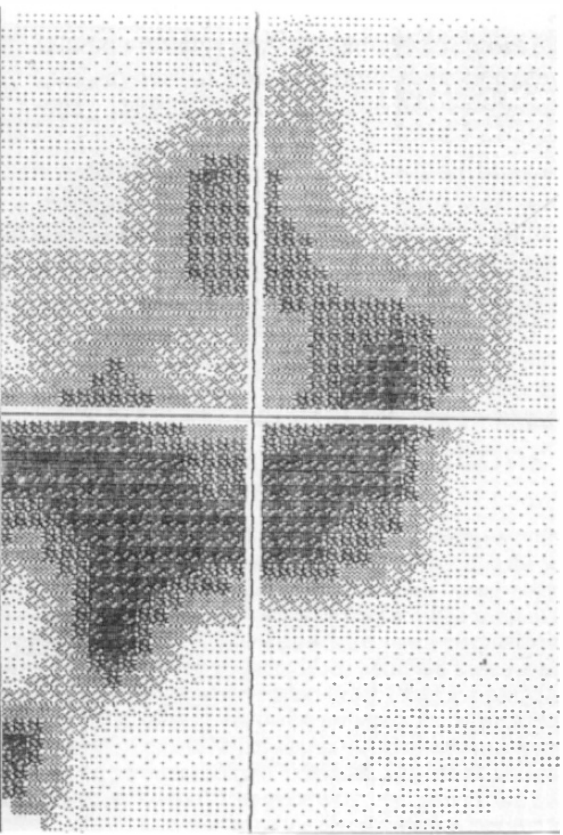

Fig 7 b.

Fig. 7 (a,b). Automatic static perimetry (b) performed one month after perifoveal laser photocoagulation (a). 
In conclusion, the pre-eminence of AMD among blinding diseases is due to the exudative form which is the leading cause of severe loss of vision.

Patients rarely present in the referral centres with localised, extrafoveal and welldefined new-vessels, amenable to focal laser treatment.

Mostly, they have a diffuse decompensation of retinal pigment epithelium with extensive subretinal neovascularisation and subfoveal new vessels initially or secondarily (due to spontaneous extension or to recurrences after laser treatment).

Natural history studies have shown that subfoveal new vessels are the most severe threat to central vision.

The perifoveal laser pilot study has brought evidence of benefit for preservation of reading vision with low vision aids, after one year follow-up. This treatment could improve the patient's quality of life.

Since it may, at best, only preserve visual acuity at the level of $20 / 200$, this motivates us to find new approaches for preventive treatment . . . for example, rehabilitation or transplantation of RPE cells? ...

\footnotetext{
References

${ }^{1}$ Ferris FL, Fine SL, Hyman L: Age related macular degeneration and blindness due to neovascular maculopathy. Arch Ophthalmol 1984, 102: 1640-2.

${ }^{2}$ Coscas G, and Soubrane G: Photocoagulation des néovaisseaux sous-rétiniens dans la dégénérescence maculaire sénile par laser à argon: résultats de l'étude randomisée de 60 cas. Bull Mem Soc Fr Ophthalmol 1983, 94: 149-54.

${ }^{3}$ Macular Photocoagulation Study Group: Argon laser photocoagulation for senile macular degeneration: results of randomized clinical trial. Arch Ophthalmol 1982, 100: 912-18.
}

+ Moorfields Macular Study Group: Argon laser photocoagulation for senile macular degeneration: results of a randomized clinical trial. $\mathrm{BrJ}$ Ophthalmol 1982, 66: 745-53.

${ }^{5}$ Macular Photocoagulation Study Group: Laser treatment trial for subfoveal neovascular membranes in the Macular Photocoagulation Study. Ophthalmology 1988, 9 (suppl): 188.

${ }^{6}$ Bressler SB, Bressler NM, Fine SL, et al.: Natural course of choroidal neovascular membranes within the foveal avascular zone in senile macular degeneration. Am J Ophthalmol 1982, 93: 157-63.

${ }^{7}$ Guyer DR, Fine SL, Maguire MG, Hawkins BS, Owens SL, Murphy RP: Subfoveal choroidal neovascular membranes in age-related macular degeneration. Visual prognosis in eyes with relatively good initial visual acuity. Arch Ophthalmol 1986, 104: 702-5.

${ }^{8}$ Coscas G, Soubrane G, Ramahefasolo C: Perifoveal laser treatment for subretinal new vessels in agerelated macular degeneration. Doc Ophthalmol Proc Series 1987, 50: 241-5.

${ }^{9}$ Coscas G, Soubrane G, Kogon P: Long-term natural history of subfoveal new vessels in age-related macular degeneration. Invest Ophthalmol Vis Sci 1989, 30 (suppl): 77.

1" Singerman LJ, Wong B, Ai E, Smith S: Spontaneous visual improvement in the first affected eye of patients with bilateral disciform scars. Retina 1985, 5: 135-43.

${ }^{11}$ Jalkh AE, Avila MP, Trempe CL, McNeil JW, Schepens CL: Choroidal neovascularization in fellow eyes of patients with advanced senile macular degeneration. Arch Ophthalmol 1983, 101: 1194-7.

${ }^{12}$ Yassur Y, Axer-Siegel R, Cohen S: Treatment of neovascular senile maculopathy at the foveal capillary free zone with red krypton laser. Retina 1982, 2: 29-46.

${ }^{13}$ Boldrey EE: Foveal ablation for subfoveal choroidal neovascularization. Ophthalmology 1989, 96: $1430-6$.

${ }^{14}$ Decker WL, Grabowski WM, Annesley WH: Krypton red laser photocoagulation for subretinal neovascular membranes located within the foveal avascular zone. Ophthalmology 1984, 91: 1582-6. 